\title{
Assessment and Management of Developer Company Competitiveness in the Conditions of Business Changes
}

\author{
Svetlana Uvarova ${ }^{1 *}$, Dmitrii Voronov ${ }^{2}$ and Sergei Erypalov ${ }^{3}$ \\ ${ }^{1}$ Voronezh State Technical University,14, Moskovsky prospect, Voronezh, 394026, Russia \\ ${ }^{2}$ UMMC Technical University, Uspenskiy Ave. 3, VerkhnayaPyshma, Sverdlovsk region, 624091, \\ Russia \\ ${ }^{3}$ Ural Federal University named after the first President of Russia B.N. Yeltsin. 19 Mira st., \\ Ekaterinburg, 620002, Russia
}

\begin{abstract}
Based on the analysis and assessment of modern of dynamics of organizational-economic changes, performed by the authors, there was revealed the necessity of improvement of approaches to the assessment and management by the companies' competitiveness. Main fluctuations of the system of management by construction complex were defined and their influence on the level of competitiveness as both largest companies of the industry and the industry group as a whole was justified. Control structure diagram of the competitiveness of the developer's company, which will lead to increasing of the business capitalization, imperative of which is high competitive stability, was proposed on the basis of the performed analysis.
\end{abstract}

\section{Introduction}

Problems of assessment of the companies' competitiveness in conditions of the volatile economic environment, characterized by the opposite transformation vector in our country (country's accession in the WTO - sanctions regime implementation) have their special applicability. Today, the valuable imperative of the world economy development is the establishment of the postindustrial economy, characterized by the determinacy of knowledge as a key competence, the formation of information-communicative basis, which determines the role of innovations. Essential competitiveness transformation, systems of its assessment and management techniques are necessary in these conditions [1,2].

\section{Methods}

It's necessary to perform the logical-semantic analysis of the key concepts of the research areas, to build the conceptual flow chart of the interconnections of the competitiveness

\footnotetext{
*Corresponding author: uvarova_s.s@,mail.ru
} 
formation process and reveal promising directions with purposes of consideration of the modern trends (fig.1).

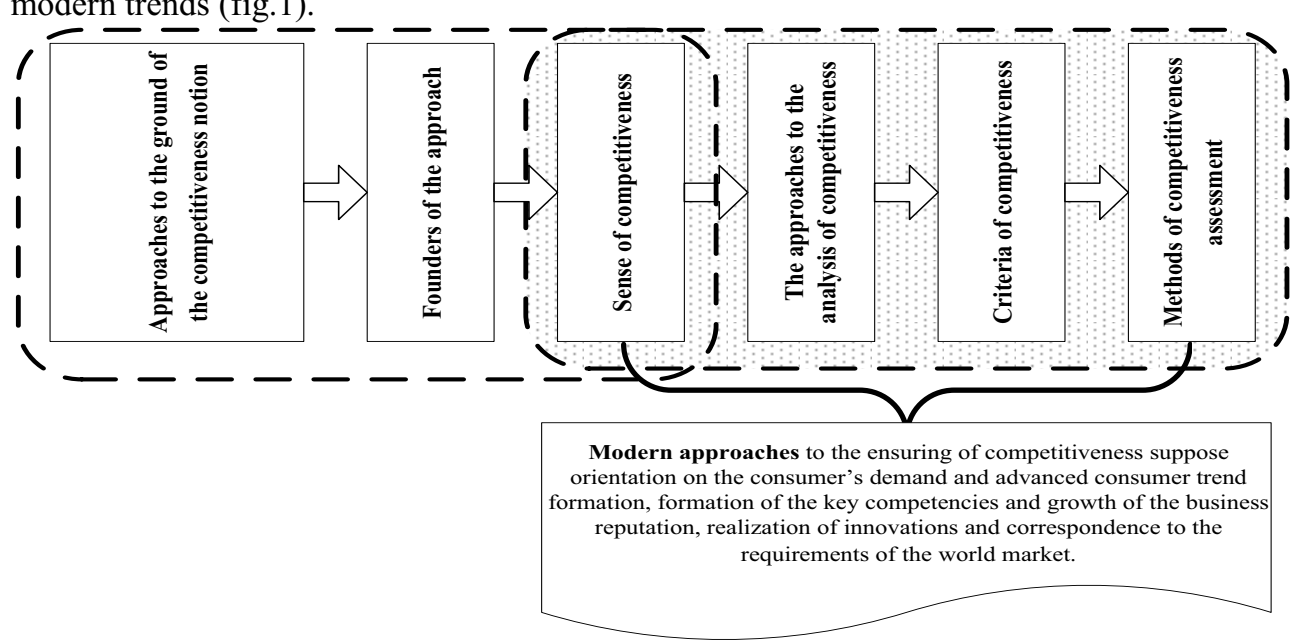

Fig. 1.Principle diagram of interconnections of the competitiveness formation process

Competitiveness, as multidimensional and multifaceted concept, is closely related to the dynamics of the environment. Postulating high degree of correlation between the dynamics of the construction complex competitiveness and dynamics of its external environment, main trends should be formulated and attractors of the development of the construction complex of the country should be revealed. Focusing on the assessment of the competitiveness of the companies of the construction complex, it should be noted that, in spite of the positive trends ("raw products-innovation-resource saving" and "creation of the high-qualitative consumer market") [3], the dynamics of the main results of the construction complex activities is liable to variations. Floats, forced vibrations and selfinduced vibrations are distinguished in the no equilibrium systems, which include the construction complex. Forced vibrations occur under the influence of oscillating of the external force on the system (for example, the influence of the global economic crisis), as a result of which, sooner or later, system starts to fluctuate with the frequency and amplitude imposed by the external influence. This type of fluctuations can be attributed to spontaneous changes caused by the external fluctuations. Consequently, fluctuations of the external environment, trends of the dynamics of the economic system of the country and world due to the period of cyclicism should be considered at planning of the events for increase of competitiveness of the company, change or selection of the competitive strategies of the company and business.

Action of external fluctuations, along with the self-organization of the economic system lead to the appearance of the several possible trajectories and attractors of the system development. There are a lot of potential system development trajectories, but knowledge of the resonant excitation, correction retraction and cumulative effect allow to predict the possibility of selection of this or that branch by the system, because random fluctuations are exposed to these effects too.

Economic model of the dynamic system behavior must be built, phase image must be determined and possible attractors must be revealed for determination of the possible attractors. Feasibility of application of methods of the phase curves creation is caused by accidental nature of economic dynamics of the construction complex.

We think it expedient to consider the construction complex the indicators, which characterize the results of its functioning in three projections, which are the resource 
provision of activity, temporary projection, efficiency of activity as phase variables, when studying its development [4]. Dynamics of capital investment, shell and core amount, commissioning of construction projects, construction in progress, the profitability of the construction can be considered such variables (fig. 2, 3, 4).

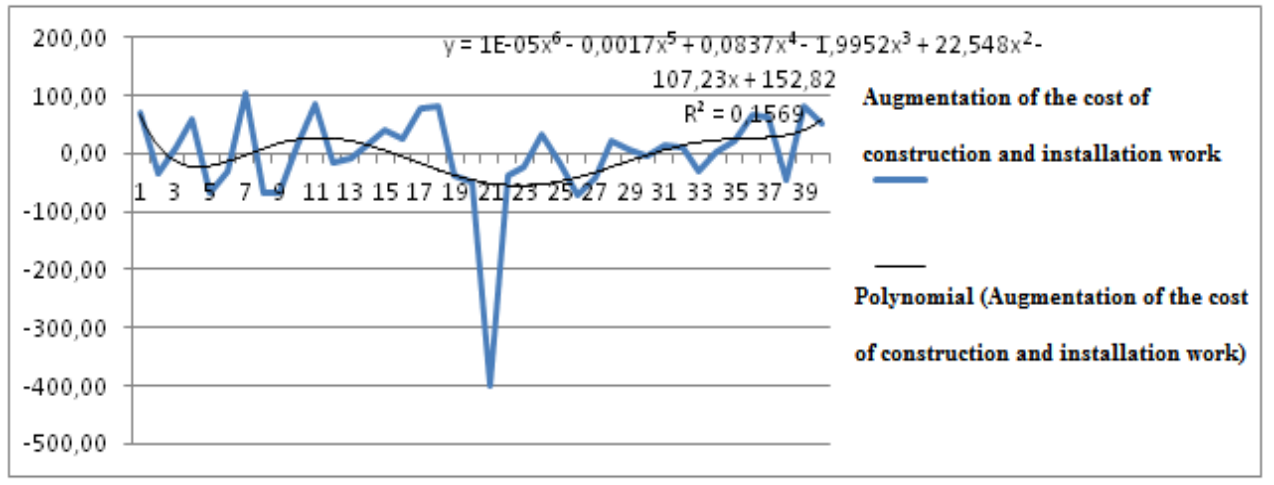

Fig.2. Formalization of the cost of construction and installation work, $\%$

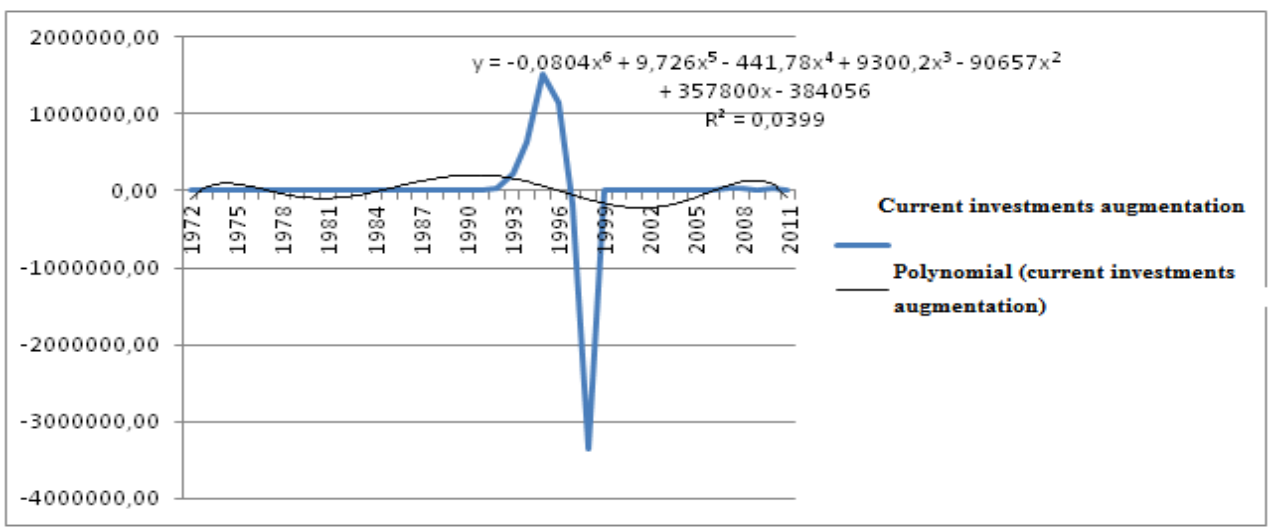

Fig. 3. Formalization of capital contributions dynamics increase, $\%$

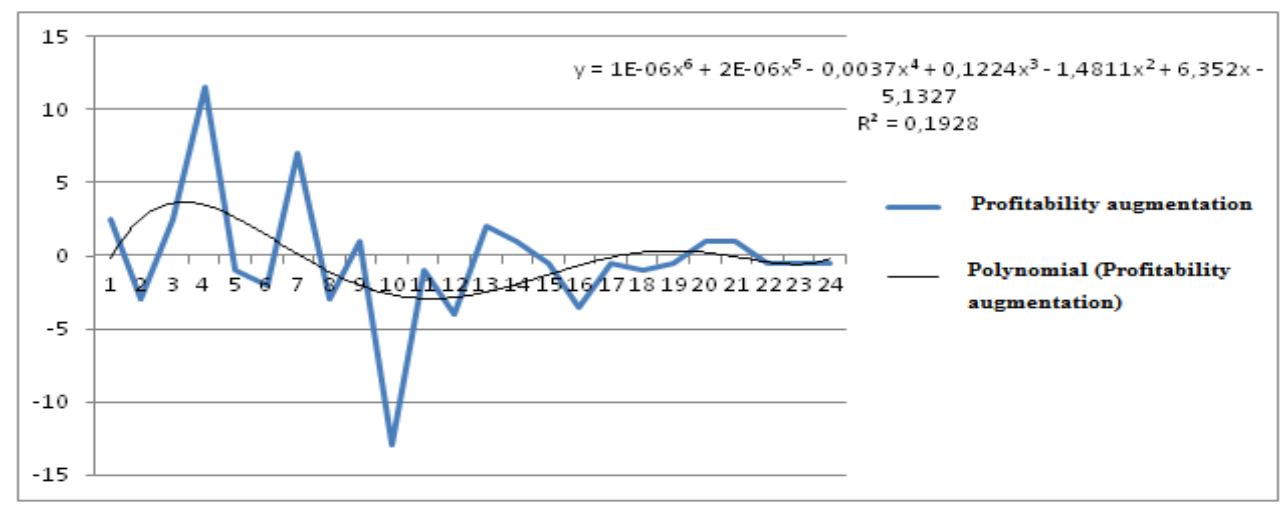

Fig. 4. Formalization of the growth dynamics of return, $\%$ 
Conclusion about maximum two stable attractors can be made during the analysis of phase images of the construction complex management system on a number of indicators (fig. 5).

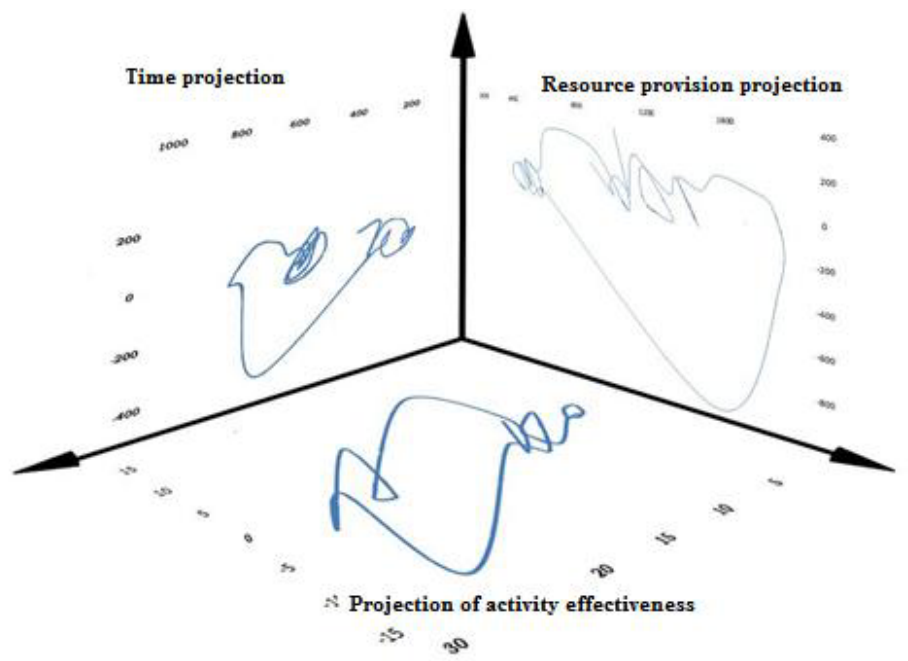

Fig. 5 Phase portrait of the building complex management system development in three projections

Conclusion about finding of the construction complex management system on the transition curve stage is based on the results of design and analysis of the phase curves of the construction complex by the scalar historical series of the investment schedule, shell and core amount, commissioning of construction projects, construction in progress, profitability of the construction.

Results of the performed analysis indicate the dependence of fluctuations of the construction industry, primarily, on the economic situation in the country. Mathematically it means that periodic trajectory was selected as an attractor by the management system of the construction complex. Projected growth or stabilization of macroeconomic indicators gives the opportunity to rest primarily on the internal system fluctuations at forecasting of the development attractors [5].

\section{Results}

Internal fluctuations of the company management system are reflected in the level of its competitiveness. Assessment of competitiveness of the company is quite subjective because of absence of the single method of assessment [6]. As a criterion of competitiveness criteria, we offer the assessment, obtained as a result of the dynamic method usage. Dynamic method involves the identification of key indicators of activity of the economic entity and application $\mathrm{f}$ the dynamic analysis to them. As the key performance indicators of the activity of the company are: operational efficiency (profitability of economic activities), strategic positioning (dynamic of the market share), as well as financial stability (liquidity). Then, by integration of the pointed indicators into a single index, assessment of the investigated company's competitiveness is performed [7].

We performed the assessment of the level of competitiveness of the leading construction companies of Russia, based on the reduced methodology. At that, we assessed the companies, which perform their activity in the field of civil engineering firstly. This choice is dictated by the fact that indexes of the construction companies, which perform industrial engineering, more depend on the realization of the large infrastructure projects, at the result 
of which these criteria can't reflect the true situation in the construction industry representatively. Besides, we can assess competitive status only of those companies, which publish their accounting [9]. Based on the above, assessment of the level of competitiveness of some of the largest construction companies.

Table 1.Indicators of the competitiveness of construction companies (K)

\begin{tabular}{|l|r|r|r|r|r|}
\hline \multirow{2}{*}{\multicolumn{1}{c|}{ Company }} & \multicolumn{5}{|c|}{ Reportingperiod } \\
\cline { 2 - 6 } & \multicolumn{2}{|c|}{2012} & \multicolumn{2}{c|}{2013} & \multicolumn{2}{c|}{2014} & \multicolumn{2}{c|}{2015} & $\begin{array}{c}\text { I half of } \\
2016\end{array}$ \\
\hline LenSpetsSMU & 1.730 & 2.022 & 1.683 & 1.244 & 1.366 \\
\hline LSR Group & 0.982 & 1.031 & 1.262 & 1.000 & 1.075 \\
\hline PioneerGroup & 0.794 & 0.657 & 1.579 & 0.745 & 1.024 \\
\hline Groupofcompanies PIK & 0.821 & 0.730 & 0.498 & 0.984 & 0.751 \\
\hline $\begin{array}{c}\text { Industrygroup } \\
\text { "CivilConstruction" }\end{array}$ & $\mathbf{1 . 2 2 0}$ & $\mathbf{0 . 9 7 6}$ & $\mathbf{1 . 2 7 1}$ & $\mathbf{0 . 9 9 9}$ & $\mathbf{1 . 0 1 4}$ \\
\hline
\end{tabular}

We performed the correlation analysis of interconnections of the effectiveness criteria of activity of the construction complex in the identified key projections and assessment of competitiveness of both leading construction companies and industrial group as a whole with purposes of determination of dependence of the competitiveness level from external fluctuations.

Table 2.Correlation analysis of the competitiveness level and environmental factors

\begin{tabular}{|c|c|c|c|c|c|c|c|c|}
\hline & 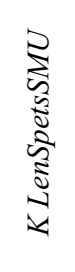 & $\begin{array}{l}5 \\
5 \\
5 \\
5 \\
5 \\
0 \\
1 \\
15\end{array}$ & 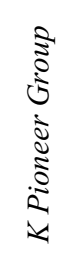 & 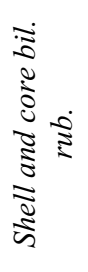 & 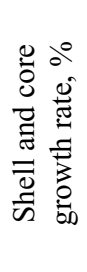 & 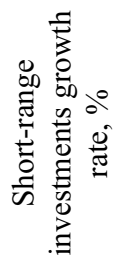 & 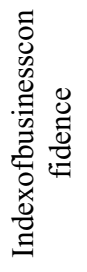 & 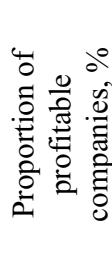 \\
\hline K LenSpetsSMU & 1 & 0.11 & $\overline{-} 04$ & 0.37 & 0.94 & 0.91 & 0.74 & 0.67 \\
\hline K Group LSR & 0.11 & 1 & 0.95 & 0.48 & -0.12 & -0.15 & 0.42 & 0.37 \\
\hline K Pioneer Group & 0.04 & 0.95 & 1 & 0.34 & 0.32 & 0.19 & 0.44 & 0.31 \\
\hline Shell and core, bil. rub & 0.37 & 0.48 & 0.34 & 1 & 0.28 & 0.72 & 0.53 & 0.93 \\
\hline $\begin{array}{l}\text { Shell and core growth } \\
\text { rate, } \%\end{array}$ & 0.94 & -0.12 & 0.32 & 0.28 & 1 & 0.53 & 0.47 & 0.58 \\
\hline $\begin{array}{c}\text { Short-range } \\
\text { investments growth } \\
\text { rate, } \%\end{array}$ & 0.91 & -0.15 & 0.19 & 0.72 & 0.83 & 1 & 0.77 & 0.91 \\
\hline $\begin{array}{l}\text { Index of business } \\
\text { confidence }\end{array}$ & 0.74 & 0.42 & 0.44 & 0.53 & 0.47 & 0.77 & 1 & 0.68 \\
\hline $\begin{array}{c}\text { Proportion of } \\
\text { profitable companies, } \\
\%\end{array}$ & 0.67 & 0.37 & 0.31 & 0.93 & 0.58 & 0.91 & 0.68 & 1 \\
\hline $\begin{array}{c}\text { K "Civil } \\
\text { Construction" } \\
\end{array}$ & 0.06 & 0.58 & 0.75 & 0.34 & 0.28 & 0.17 & 0.71 & 0.25 \\
\hline
\end{tabular}

Results of correlation analysis testifies to the presence of interconnection between environment fluctuations and competitiveness changes, but ties can be concluded on the degree of closeness and the impact of the number of other factors on the level of 
competitiveness. So, apart from the external to the process of activity of the company and its level of competitiveness affect the internal fluctuations, which represent a set of core competencies of the company or its competitive advantage. Then process of activity, which represents a complex of tactical and operational measures on the realization of competitive strategy, which can be interpreted as a set of organizational-economic changes aimed at resonance effect for achievement of the end of strategic purpose. That's why it's necessary to manage the activity of the company with consideration of the system of heredity (previous working experience, which characterizes the presence of the necessary resources and their sources), purposes of changes (maximization of the competitiveness level of the company), influence of the spontaneous variations (which characterizes the risks of the company).

\section{Discussions}

Depending on the fluctuations of the external and internal environment, as well as the existing resources of the company and approximation of management actions, certain level of competitiveness is achieved at each time point (fig. 6). It should be noted, that despite the existence of the trend line, the value of the level of competitiveness of the company between the discrete moments that characterize the stages of development, is erratic in size of the achieved results, which confirms the thesis about non-linearity of development of the company as the system [8].

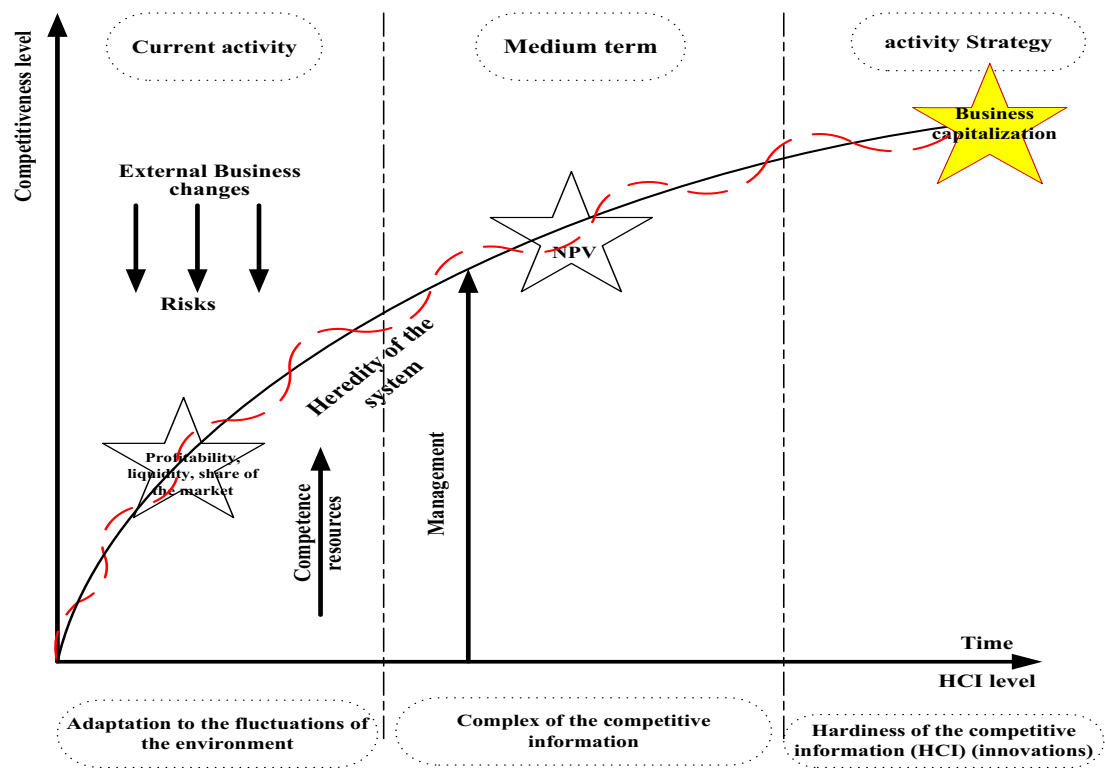

Fig. 6.Control structure diagram of the competitiveness of the company

But, company management pursues different purposes, depending on the time horizon of planning. So, the current activity is a process of adaptation changes as a response on fluctuations of the environment with the purpose to keep competitive positions and preserve the existing benefits [9]. Resources and capabilities of the company, which form its heredity and neutralize its environmental influence are determining in this interval. Key criteria in this case are the short-term results of activity, and the purpose of the development of the company management system is the achievement of their positive dynamics [10]. In the medium term, the purpose of the company is quoted results of the 
planned and ongoing projects [11], with the competitiveness level is formed by the combination of different competitive advantages, depending on the specifics of the activity of the company and market conditions. Result of the planned competitive strategies realization is, ultimately, business capitalization, imperative of which is not only the high level of the competitiveness, achieved at the expense of realization of competitive information, performance of the effective projects, success adaptation to the external fluctuations and continuous positive dynamics of the results of the current activity, but proactive control based on the formation of the market trends at the expense of realization of the sustainable competitive information [12] on the innovative basis.

\section{Conclusion}

Stable positive competitiveness dynamics, which is characterized not only be the maintenance on the current level, but by the stable growth of the indicators can be achieved only at with the continuous renewal of the technological base, organizational management structure, economic foundations of the operation on the basis of innovation. Innovations (including technological) are often a source or catalyst for sustained competitive advantages of the company. Thus, in modern conditions, characterized by unstable nonlinear dynamics of the external environment, achievement and maintenance of the high level of competitiveness are possible only at the expense of realization of sustainable competitive advantages on the innovation basis that corresponds the modern trend "raw productsinnovation-resource saving" and contributes sustainable development of the country's economy on the innovation basis.

\section{References}

1. S.V. BelyaevaO.M.Belyanceva, N.ASafonova. Sovremennayaeconomika: problemyiresheniya, 10 (58), 34-41, (2014)

2. D.S. Voronov, V. V.Krivorotov.VestnikUrFU. Seriya ehkonomika i upravlenie, 5, 717$740,(2015)$

3. V.S.KanhvaM.I.Mamaev, H.M.Gumba.Nauchnoeobozrenie, 9, (2013)

4. V.V.Krivorotov, A. V.Kalina, T. V.Matveeva, A. YU.Bajranshin. Povyshenie konkurentosposobnosti sovremennyh rossijskih territorial'no- proizvodstvennyh kompleksov, Ekaterinburg: UrFU, Ekaterinburg, (2013)

5. E.V. Nezhnikova, R.V. Obuhov. Economikaipredprinimatel'stvo,2-1(67-1), 596-600, (2016)

6. N.G. Sarkind A.V.Gafurovc I.R. Procedia Economics and Finance, 14, 23-29, (2014)

7. S.Naresh K. MalhotraJournal of Business Research, 69, 5671-5681, (2016)

8. I.M.Horta, A.S. Camanho Expert Systems with Applications, 41, 974-983, (2014)

9. J. Deng, L. Wang Swarm and Evolutionary Computation, 32, 121 -131, (2017)

10. P.Neirotti, E.Raguseo. Information \& Management, 54, 139-153, (2017)

11. R. Hou, J. Wu, H. S. Du. Statistical Mechanics and its Applications, 469,644-653, (2017)

12. S.S. Uvarova, V.S. Kankhva, S.V. Belyaeva. Procedia Engineering, 165, 1046-1051, (2016) 